\title{
Teaching mobile Web development An iPhone application design workshop at the University of Illinois Undergraduate Library
}

$\mathbf{T}$ he digital era, a time of massive unmediated access to information, has brought with it profound changes in the ways we work and live. With these changes, instructional offerings of libraries must shift if they are to remain a relevant and necessary component of information centers. A motivating factor for implementing an iPhone app design workshop stems from observations of the highly popular information environments of the 21 st-century student. The mobile landscape of information access is inclusive of a number of mobile-networked devices-one of

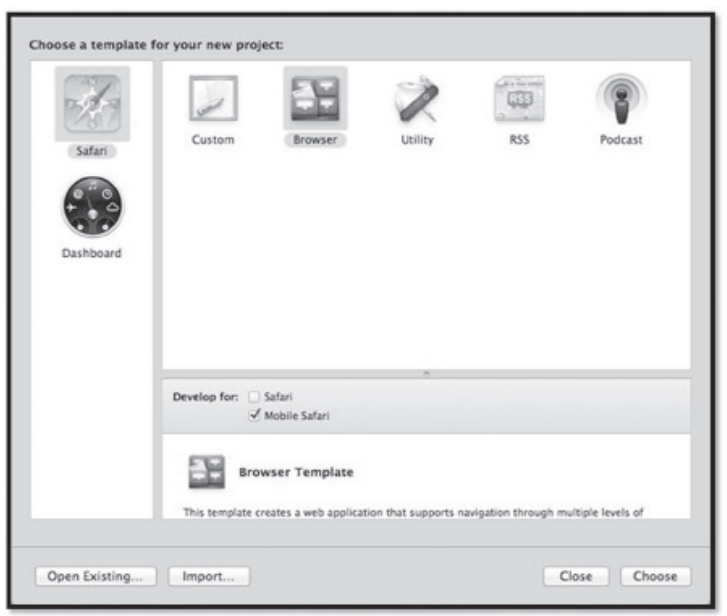

Image 1. Dashcode Templates for Mobile Apps (Image is from Dashcode, a Web-based software developer environment from Apple.) View this article online for detailed images. the most popular platforms is the iOS environment from Apple.

While not every student has an iPhone, iPad, or iPod touch, an important feature of the digital landscape is the manner in which students create and share with digital tools. Research in digital media among youth offers compelling evidence that undergraduate students value editing, creating, and sharing across many platforms. ${ }^{1}$ In an effort to support the desire among students to customize (and make relevant) their digital environments, the staff of the University of Illinois at Urbana-Champaign Undergraduate Library planned for a mobile app workshop that would be responsive to all skill levels.

Librarians and two interns from the Undergraduate Library designed and implemented two rounds of labbased workshops for mobile applications running on Apple's iOS software. Project planning included a workshop for students and an additional workshop for staff. The first round occurred in the summer semester of 2011. The second round of workshops were held in December
2011 and were re-worked for basic and advanced levels, incorporating additional templates in the iOS developer environment (see image 1).

Jim Hahn is orientation services and environments librarian, e-mail: jimhahn@illinois.edu, Jennifer Bylsma is graduate assistant, e-mail: jshepar2@illinois.edu, Elizabeth Sullivan is graduate assistant, e-mail:easulli2@ illinois.edu, at the University of Illinois at UrbanaChampaign

(c) 2012 Jim Hahn, Jennifer Bylsma, and Elizabeth Sullivan 
The workshops were capped at 40 participants. A pre-workshop survey showed that among attendees of the staff session, many were Web developers from departments on campus. The survey data also showed that there were a number of students participating from the Graduate School of Library and Information Science (GSLIS).

The purpose of this article is to provide an overview and strategies for implementing an iPhone app development workshop in an academic library setting. We also enumerate challenges that needed to be overcome in order to create the iOS workshop. The summer workshops were scoped towards beginners in mobile application design and do not assume previous background experience in software design or programming with compiled languages. The second round offered an additional app design workshop for advanced design that would give students the ability to upload apps to the app store and incorporate additional dynamic data from data sources across the Web.

\section{Planning}

Space and software

Initial planning involved identifying computing resources that any participant could use. The workshop necessitated an Apple developer environment and so the workshop was in need of an iMac lab. In addition to making use of Apple computers, the lab needed the iPhone Software Developer Kit (SDK) installed on all lab stations. This proved to be an obstacle since parts of the Apple license agreement cannot be guaranteed in an open lab environment. We were able to work around this limitation by not installing the full SDK, but rather used the Dashcode environment without the full SDK enabled. This posed a limitation in that we could not make use of the full iOS simulator, but rather simulated app performance to a Safari Web browser. After negotiating with our lab partners for the needed software, we were able to move forward with the pilot workshop.

\section{Web-based design approach}

The Dashcode Developer environment is geared toward Web-based mobile application development. This Web-based approach allows students with Web authoring proficiency to style HTML pages with library data sources to create library applications. $^{2}$

\section{Workshop staff}

Workshop staff included students from GSLIS who were able to contribute to the instructional design of the workshop. Graduate student instructors were enrolled as interns or practicum students over the summer months, and also went through hands-on training by library staff that has experience with Webbased mobile application design. The resource material guiding application design is a recent book-length work on designing iOS apps with Web skills. ${ }^{3}$

\section{Teaching the summer workshop}

The library's main objective for the summer workshop was for all participants to have designed a functional prototype of an RSS app (see images 2 and 3). The app incorporates RSS information into mobile presentation on the mobile Safari browser. The framework for this app is a template from Dashcode; students provided a feed and also modified the look and feel of the app from the Dashcode editor (see image 4). 
The staff section had a full lab of 40 attendees on the day of the event. Nearly 20 people registered for the student section; however, only ten attended. The format used for both sessions of the workshop was to follow a short lecture familiarizing attendees with the layout of the Dashcode developer environment and basic workflow steps used to create an RSS feed app.

The second portion of the workshop was devoted to hands-on design of apps. Three library staff were available for troubleshooting and answering questions during the hands-on portion of the workshop. Image 4 shows the developer environment where each participant could customize an RSS feed for

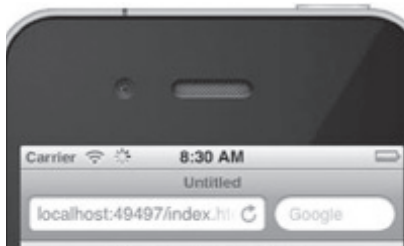

\section{New Books} SATURDAY, DECEMAER 31, 20,

Politics in Africa : a new introduction /
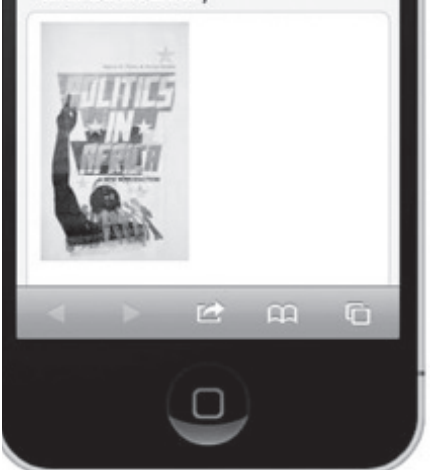

Image 3. Prototype of the RSS app, second level view. (Image is from the iPhone simulator, a Product of Apple, Inc.)

\section{(6) की}

valuable to them and that the workshop stimulated their interest. However, the answers to the questions about other things that the attendees would have liked to learn, improvements for future workshops, and comments revealed that there were several topics the attendees would have liked to see covered in more depth.

Several attendees were unhappy with the narrow focus on the RSS feed functionality of Dashcode, as they had expected to receive a more global view of Dashcode's functionality and get some exposure to developing other kinds of apps. Other attendees referred to technical problems soaking up workshop time, both in terms of getting logged into mobile app presentation. Images 3 and 4 show finished product of student's hands- on work, a functioning prototype of an RSS app.

The example RSS app developed in the workshop is powered by the University of Illinois New Titles feed (www.library.illinois.edu /newtitles/), which is a tool that creates a desired RSS feed of recently cataloged items in the library collection.

\section{Exit survey responses from summer workshop}

The exit survey for the event revealed one major theme: attendees left both satisfied and hungry for more knowledge. All 13 respondents to the exit survey either agreed or strongly agreed that the resources given would be

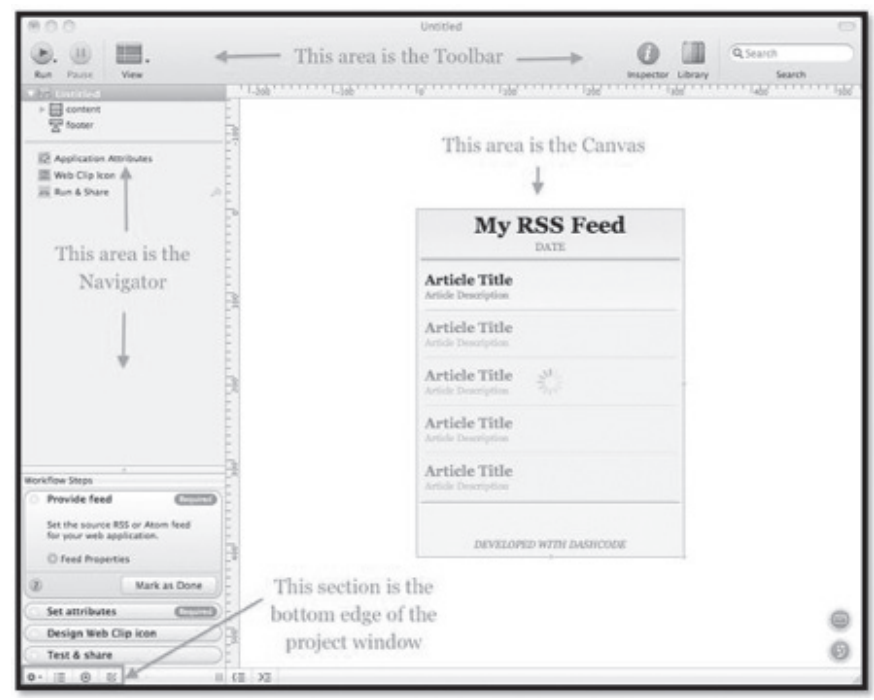

Image 4. The basic development environment that was used in all workshops. (Image is from Dashcode, a Web-based software developer environment from Apple, Inc.) 
details about how to acquire Dashcode. The overwhelming theme was that the workshop was too short. One attendee even thought the workshop could run double the length (two hours) next time.

The format of short lecture followed by hands-on practice time received mixed reviews. One person commented that they liked the format and transition among instructors. Giving the attendees a great deal of individual work time did allow the presenters to diagnose the individual problems with each of the apps effectively, and also gave the presenters time to address some more personalized and advanced questions, such as providing more detail on how to actually host apps.

\section{Second iteration of the workshop}

Two workshops were designed for December that incorporated the exit survey responses from the summer-the biggest change was to design an advanced-level workshop, in addition to covering more material in the beginner's workshop.

In the December iteration of the workshop, the material was expanded to cover additional templates from the developer environment. Sensing also that the staff and student divisions were unnecessary, the library instead developed workshops that would respond to skill level regardless of university affiliation. The beginner workshop now includes coverage of two templates: the RSS template as well as the Browser template.

The library also designed an advanced workshop. The turnout of more experienced participants influenced our ideas for the advanced workshop. This workshop is more content heavy with less hands-on time, since we had possibly given too much time to the exploring portion in the initial workshop.

In the advanced workshop participants learned to edit data sources of the Browser template and were introduced to the iPhone's native developer environment, the Xcode module of the iOS. The library does not currently have the full SDK loaded on the Macs in the lab but was able to make use of screenshots as well as online screencasts to deliver foundational content in the Xcode module. The final portions of the Xcode workshop covered the process for uploading Dashcode-developed applications to the iTunes app store.

\section{Other planned delivery modes}

An online version of the workshop has also been proposed. The online version would have several key differences, one being that users logging in remotely are not all going to have Mac computers as supplied in the computer lab at the library. Even if all the participants had a Mac computer, requiring that the entire iOS SDK be installed onto their system in preparation for the workshop does not encourage those who are simply curious about app development to attend the workshop.

The platform that we plan to use for the online offering is Elluminate Live! Our decision to use this particular platform resides in the fact that GSLIS uses the Elluminate Live! tool to coordinate simultaneous sessions with people logged in remotely from across the country. Also since the request for an online workshop came from an affiliate of GSLIS, it seemed pertinent to design an online version in cohesion with the system already in place with that program.

Using this system we plan on running this workshop live with active LEEP participants (students who attend GSLIS remotely). Since a hands-on portion of the workshop would not be an option in an online environment, most of the instruction would be in the form of application share, where the instructor takes the participants on a virtual tour of the Dashcode platform. During this live demonstration, the instructor can answer questions in real time as he or she walks through the various elements of the program. We would use an edited version of the recording of this workshop to craft a video file that we could post in our corresponding Lib Guide ${ }^{4}$ for those unable to make the on campus workshop or the online version but would still like to go over the material. 


\section{Lessons learned}

There are a variety of user types and motivations for attending iPhone workshops. One of the biggest challenges in creating and delivering a technology workshop such as this is the need to respond to individual's levels of technology competence and familiarity. In order to alleviate these challenges, there should be adequate trained staff to respond to questions during hands-on portions. A new feature for future lab-based learning will be to create open lab time where students and staff could ask questions of staff based on the apps they need to create; having such open lab time to supplement instructional delivery will help to meet learner's individualized paces for learning and mobile application design.

The library is planning to further support student design teams, and these workshops have given the Undergraduate Library a starting point in recruiting student design teams that will help to codesign mobile apps for library services. From these workshops important student contacts are formed, and the library is recruiting design teams that are not solely from computer science departments, but that are from student organizations not typically associated with application development.

It is this population that may yield great results for mobile tools that offer the broadest relevance to students' everyday information needs, and may help further to connect library resources into the students' academic

("Learning to ....", cont. from page 393)

\section{Notes}

1. Jack London, "Getting into Print," The Editor, March 1903, 57.

2. Milton D. Cox, "Introduction to Faculty Learning Communities," New Directions for Teaching and Learning 97 (2004): 8-9, 18.

3. See Gerald Graff and Cathy Birkenstein, They Say/I Say, 2006.

4. Allyson Washburn, "Writing Circle Feedback: Creating a Vibrant Community of Scholars," Journal of Faculty Development 22, no. 1 (2008): 33-35.

5. Cynthia Tysick and Nancy Babb, "Writing Support for Junior Faculty Librarians: A work, a desired outcome of any library workshop.

\section{Conclusion}

Technology workshops in general and mobile computing training in particular will form a vital component of the instructional portfolio of academic libraries as more students look to the library for technology training and experimentation. Libraries are forging new ways in which to be vital to student needs by delivering tailored instruction in mobile application development. While it is often stated that with mobile tools, "there is an app for that," perhaps libraries can show their cutting- edge instructional value in this new arena by bringing to campus a "workshop for that."

\section{Notes}

1. M. Ito, et al., Hanging Out, Messing Around, and Geeking Out: Kids Living and Learning with New Media (Cambridge, MA: MIT Press, 2009).

2. As an example of library iPhone application developed using this method, see the University of Illinois experimental apps page at www.library.illinois.edu/ugl/about /Experimental_iPhone_Apps/iPhone_apps. html (accessed June 7, 2012).

3. J. Hahn, iPhone Application Development: Strategies for Efficient Mobile Design and Delivery (Oxford: Chandos, 2011).

4. http://uiuc.libguides.com/iphone. $\boldsymbol{n}$

Case Study," The Journal of Academic Librarianship 32, no. 1 (2006): 97-99.

6. Martha C. Petrone and Leslie OrtquistAhrens, "Facilitating Faculty Learning Communities: A Compact Guide to Creating Change and Inspiring Community," New Directions for Teaching and Learning 97 (2004): 67.

7. Donald E. Hall, The Academic Community: A Manual for Change (Columbus: Ohio UP, 2007), 140.

8. Martha C. Petrone and Leslie OrtquistAhrens, "Facilitating Faculty Learning Communities," in Building Faculty Learning Communities (Jossey-Bass, e-book), 64-66. n 